\title{
Genetic Variability and Its Implications on Early Generation Sorghum Lines Selection for Yield, Yield Contributing Traits, and Resistance to Sorghum Midge
}

\author{
Massaoudou Hamidou (iD, ${ }^{1,2}$ Abdoul Kader M. Souley, ${ }^{1}$ \\ Issoufou Kapran, ${ }^{1}$ Oumarou Souleymane, ${ }^{1,2}$ Eric Yirenkyi Danquah, ${ }^{2}$ \\ Kwadwo Ofori, ${ }^{2}$ Vernon Gracen, ${ }^{2,3}$ and Malick N. Ba ${ }^{4}$ \\ ${ }^{1}$ Institut National de la Recherche Agronomique du Niger (INRAN), BP 429, Niamey, Niger \\ ${ }^{2}$ West Africa Centre for Crop Improvement, University of Ghana, PMB 30, Legon, Accra, Ghana \\ ${ }^{3}$ Department of Plant Breeding and Genetics, Cornell University, 520 Bradfield Hall, Ithaca, NY 14850, USA \\ ${ }^{4}$ International Crops Research Institute for the Semi-Arid Tropics, BP 12404, Niamey, Niger \\ Correspondence should be addressed to Massaoudou Hamidou; hmassaoud@yahoo.fr
}

Received 11 December 2017; Revised 13 February 2018; Accepted 5 March 2018; Published 8 April 2018

Academic Editor: Kassim Al-Khatib

Copyright (C) 2018 Massaoudou Hamidou et al. This is an open access article distributed under the Creative Commons Attribution License, which permits unrestricted use, distribution, and reproduction in any medium, provided the original work is properly cited.

\begin{abstract}
Sorghum is the second most important cereal crop in Niger. The crop is grown in a wide range of ecological environments in the country. However, sorghum grain yield in Niger is limited by both abiotic and biotic constraints. Recombinant inbred lines derived from the cross of a local variety with a midge resistant variety and two local checks were evaluated during the 2015 rainy season across two planting dates in two environments in Niger. The objective was to investigate genetic variability for yield, yield related traits, and resistance to sorghum midge. High phenotypic coefficient of variation (PCV) versus genotypic coefficient of variation (GCV) was observed in both sites and planting dates. Across planting dates at both Konni and Maradi, grain yield, plant height, panicle weight, and midge damage had high heritability coupled with high estimates of genetic advance. At Konni, high genetic advance coupled with high heritability was detected for grain yield, plant height, panicle weight, and resistance to midge. There were similar results at Maradi for grain yield, plant height, and panicle weight. Therefore, selection might be successful for the above characters in their respective environments.
\end{abstract}

\section{Introduction}

Sorghum (Sorghum bicolor L. Moench) is the second most important cereal crop in Niger after pearl millet. It is used in both human nutrition and animal nutrition. In Niger, sorghum production rarely meets the demand of the growing population. Grain sorghum yields are very low, about 0.280 tons/ha, which is far below the genetic potential of the crop compared to countries like USA (4.3 tons/ha), Argentina (4.9 tons/ha), and China (3.2 tons/ha) according to FAOSTAT [1]. The low production is attributed to abiotic and biotic stress such as sorghum midge Stenodiplosis sorghicola. Sorghum midge is a panicle insect found in most of the sorghum growing environments in Niger, where it causes high grain yield reduction on sorghum crop. Grain yield reduction due to midge of about $56 \%$ to $67 \%$ was documented on local sorghum varieties in Niger compared to $14 \%$ to $17 \%$ yield reduction observed on introduced, midge-resistant sorghum genotypes (Kadi Kadi et al.) [2]. These data indicate that local sorghum varieties grown in Niger are highly susceptible to midge infestation. The use of indigenous varieties with low yielding capacity also limits sorghum productivity in Niger. Farmers mostly rely on low-yielding landraces, so sorghum production fails to meet demand of increasing population and food insecurity remains a major issue (Maman et al.) [3]. Hence, it is essential that plant breeders develop and provide farmers with new improved sorghum cultivars. To stabilize sorghum production in Niger, identification 
of superior cultivars in terms of yield and resistance to sorghum midge is of major importance. Identification of genotypes with desirable traits and their subsequent use in breeding and establishment of suitable selection criteria can be helpful for successful varietal improvement programs. Analysis of variability among the traits and the association of a particular character with other traits contributing to yield of a crop would be of great importance in planning a successful breeding program (Mary and Gopalan) [4]. In planning sorghum improvement program, knowledge of variability of traits could be a key to the success. Comparative variability of traits is evaluated by estimating the genotypic coefficient of variation (GVC) and the phenotypic coefficient of variation (PCV) (Ahmad et al.) [5]. According to Sami et al. [6], heritable genetic effects and nonheritable environmental effects contribute to variability found in germplasm. The GCV expresses the heritable portion, while the PCV is an expression of both the genetic and environmental effects on the trait (Bello et al.) [7]. In sorghum, several studies on genetic variation have been documented. In a study of genetic variation, Warkad et al. [8] reported high genotypic and phenotypic coefficient of variation for yield and yield related traits in sorghum germplasm. Dhutmal et al. [9] also reported high genotypic and phenotypic coefficient of variation for grain yield and its components in drought-tolerant sorghum. It has been observed that the estimates of genetic variance were smaller than their respective phenotypic variances (Khan et al.) [10].

Heritability provides information on the transmissibility of traits from one generation to another. Knowledge of heritability determines the selection methods a breeder can use which could be appropriate for the improvement of traits in plants as reported [11]. Heritability is an estimating factor and indicates the consistency of a particular phenotypic observation that directs a breeding value (Falconer and Mackay) [12]. High heritability of a trait gives an indication of the progress that can be made for the improvement of that trait. However, in the absence of genetic advance, broad sense heritability may not be reliable. Therefore, broad sense heritability estimation needs to be coupled with the estimations of genetic advance for a more accurate assessment as described $[13,14]$.

Genetic variation evaluation that provides information on parameters like genotypic coefficient of variation, phenotypic coefficient of variation, heritability estimates, and genetic advance is absolutely necessary to start an efficient breeding program (Atta et al.) [15]. This investigation was undertaken to estimate genotypic and phenotypic coefficient of variation, heritability, and genetic advance for yield and resistance to sorghum midge in early sorghum generation.

\section{Materials and Methods}

2.1. Experimental Germplasm. 280 recombinant inbred lines and two local checks were evaluated. These F5 lines were obtained by crossing a local sorghum variety (MDK) and an exotic sorghum midge-resistant cultivar from ICRISAT (ICSV88032) with progeny advanced using single seed descent (SSD). The local variety has white grain with good qualities; it is widely cultivated by sorghum farmers in Niger. However, this variety is photosensitive and highly susceptible to sorghum midge.

2.2. Experimental Sites. The study was carried out during 2015 rainy season at the research stations of INRAN at Konni and Maradi. Both locations are sorghum midge hotspot in Niger. Konni has a latitude of $13^{\circ} 47^{\prime} 23^{\prime \prime}$ north and a longitude of $5^{\circ} 14^{\prime} 57^{\prime \prime}$ east and the average annual rainfall of $589.7 \mathrm{~mm}$ with average temperature of $29.3^{\circ} \mathrm{C}$. Maradi has a latitude of $13^{\circ} 18^{\prime} 25^{\prime \prime}$ north and a longitude of $7^{\circ} 09^{\prime} 35^{\prime \prime}$ east and the average annual rainfall of $537.4 \mathrm{~mm}$ with average temperature of $20.5^{\circ} \mathrm{C}$.

2.3. Experimental Design. The experimental design was an alpha (0.1) lattice with 2 replications in two different planting dates, giving four environments. However, blocking was not significant and the dates were reanalyzed using randomized complete block design. Environments one, two, three, and four were the first planting date at Konni, the second planting date at Konni, the first planting date at Maradi, and the second planting date at Maradi, respectively. The use of two different planting dates was to simulate early or late starting rainy season. Each genotype was grown in a single row of 3 meters; the intrarow and interrow spacing was $0.20 \mathrm{~m} \times 0.80 \mathrm{~m}$. The material was subjected to natural infestation of sorghum midge. In order to evaluate midge damage on the panicles, three panicles were covered at emergence using selfing bags. At harvesting, panicle and grain mass were recorded for the three covered and three uncovered panicles. The loss in grain yield in three uncovered panicles was expressed as a percentage of grain yields in covered panicles.

2.4. Data Collection and Analysis. Data collected were grain yield (GY), plant height (PH), 1000 seeds weight (TSW), days to $50 \%$ flowering (FF), midge damage (MD), and panicle weight (PW). Grain yield was measured in tons per hectare adjusted to grain moisture content at $12 \%$. $\mathrm{PH}$ was measured in centimeters from the base of the plant to top of the panicle. 1000 seeds weight was measured from counted 1000 seeds in grams. Days to $50 \%$ flowering were recorded by counting the number of days from planting to the day when $50 \%$ of the plants in a plot flowered. Midge damage was calculated as loss of grain yield in three uncovered panicles expressed as a percentage of grain yield in three covered panicles. Panicles weight was recorded by weighting the entire panicle at physiological maturity. Analyses of variance were computed for all the characters evaluated using computer software system of GenStat, 12th edition. Genetic components were calculated as follows.

Heritability in the broad sense $\left(H^{2}\right.$ or $\left.h^{2}\right)$ was estimated according to Hanson et al. [16] as follows:

$$
h^{2}=\frac{\sigma_{g}}{\sigma_{\mathrm{ph}}},
$$

where $h^{2}$ is heritability in the broad sense; $\sigma_{g}$ is genotypic variance; and $\sigma_{\mathrm{ph}}$ is phenotypic variance. 
TABLE 1: Mean square for traits across environments.

\begin{tabular}{|c|c|c|c|c|c|c|c|}
\hline Source of variation & d.f. & GY & $\mathrm{PH}$ & PW & $\mathrm{FF}$ & TSW & $\mathrm{MD}$ \\
\hline Replications & 1 & 1234336 & 191,2 & 15202 & 193,38 & 120,36 & 0,73 \\
\hline Entries & 281 & $177377^{* *}$ & $9585,4^{* *}$ & $4848^{* *}$ & $219,94^{* *}$ & $102,64^{* *}$ & $0,14^{* *}$ \\
\hline $\mathrm{PD}$ & 1 & $3548702^{* *}$ & $1287836,1^{* *}$ & $339779^{* *}$ & $49,11^{*}$ & $2005,55^{* *}$ & $50,42^{* *}$ \\
\hline Sites & 1 & $30681580^{* *}$ & $1640346,3^{* *}$ & $1087245^{* *}$ & $12805,54^{* *}$ & $100,86^{\mathrm{ns}}$ & $27,80^{* *}$ \\
\hline Entries.PD & 281 & $129768^{* *}$ & $1471^{* *}$ & $2261^{* *}$ & $70,26^{* *}$ & $77,34^{\mathrm{ns}}$ & $0,11^{* *}$ \\
\hline Entries.Sites & 281 & $119234^{* *}$ & $1159,3^{* *}$ & $3165^{* *}$ & $72,01^{* *}$ & $80,28^{\mathrm{ns}}$ & $0,15^{* *}$ \\
\hline PD.Sites & 1 & $7723780^{* *}$ & $16797^{* *}$ & $258654^{* *}$ & $379,18^{* *}$ & $3829,83^{* *}$ & $9,99^{* *}$ \\
\hline Entries.PD.Sites & 281 & $104061^{* *}$ & $987,5^{\text {ns }}$ & $2603^{* *}$ & $38,59^{\text {ns }}$ & $67,06^{\text {ns }}$ & $0,12^{* *}$ \\
\hline Residual & 1127 & 62286 & 852,4 & 1540 & 49,91 & 64,47 & 0,06 \\
\hline $\mathrm{CV}$ & & 65,3 & 15,4 & 42,5 & 10,2 & 39,5 & 69,6 \\
\hline
\end{tabular}

GY: grain yield; PH: plant height; PW: panicle weight; FF: days to 50\% flowering; TSW: 1000 seeds weight; MD: midge damage; PD: planting dates; ns: not significant; ${ }^{* *}$ significant at $1 \% ;{ }^{*}$ significant at $5 \%$.

TABLE 2: Mean square for traits in the first planting date at Konni.

\begin{tabular}{lccccccc}
\hline Source of variation & d.f. & GY & PH & PW & FF & TSW & MD \\
\hline Replications & 1 & 2421264 & 4.8 & 10795.5 & 38.49 & 28.5 & 1.56515 \\
Entries & 281 & $101337^{* *}$ & $4270.8^{* *}$ & $1451.8^{* *}$ & $95.47^{*}$ & $184.9^{*}$ & $0.14143^{* *}$ \\
Residual & 281 & 66375 & 647.9 & 643.6 & 79.77 & 190.6 \\
CV & & $\mathbf{5 3 . 8}$ & $\mathbf{1 0 . 5}$ & $\mathbf{3 5 . 4}$ & $\mathbf{1 2 . 5}$ & $\mathbf{3 5 . 5}$ & $\mathbf{4 8 . 1}$ \\
\hline
\end{tabular}

GY: grain yield; PH: plant height; PW: panicle weight; FF: days to 50\% flowering; TSW: 1000 seeds weight; MD: midge damage; ns: not significant; ${ }^{* *}$ significant at $1 \% ;{ }^{*}$ significant at $5 \%$.

Genotypic and phenotypic variances were calculated according to Burton [17] as follows:

$$
\begin{aligned}
\sigma_{g}^{2} & =\frac{\mathrm{MS} 1-\mathrm{MS} 2}{r}, \\
\sigma_{\mathrm{ph}}^{2} & =\frac{\mathrm{MS} 1}{r},
\end{aligned}
$$

where $\sigma_{g}^{2}$ is genotypic variance; $\sigma^{2}$ ph is phenotypic variance; MS1 is mean square for the entries; MS2 is mean square for the residuals; and $r$ is replication.

Genotypic coefficient of variance (GCV) and phenotypic coefficient of variance (PCV) were determined according to Burton [17] as follows:

$$
\begin{aligned}
& \mathrm{GCV} \%=\frac{\sqrt{ } \sigma_{g}^{2}}{X} * 100, \\
& \mathrm{PCV} \%=\frac{\sqrt{ } \sigma_{\mathrm{ph}}^{2}}{X} * 100,
\end{aligned}
$$

where GCV is genotypic coefficient of variance; PCV is phenotypic coefficient of variance; $\sigma_{g}^{2}$ is genotypic variance; $\sigma^{2}{ }_{\mathrm{ph}}$ is phenotypic variance; and $X$ is sample mean.

Genetic advance (GA) was calculated according to Johonson et al. [18] as follows:

$$
\mathrm{GA}=k * \sigma_{\mathrm{ph}} * h^{2},
$$

where GA is genetic advance; $K$ is a constant $=20.06$ at $5 \%$ selection intensity; $\sigma_{\mathrm{ph}}$ is square root of phenotypic variance; $H^{2}$ is heritability in the broad sense; and

$$
\mathrm{GA} \text { as } \% \text { of mean }(\mathrm{GAM})=\left(\frac{\mathrm{GA}}{\text { mean value }}\right) * 100 \text {. }
$$

\section{Results}

3.1. Analysis of Variance. Across environments, entries and planting dates were significant $(P<0.001)$ for all traits, while sites displayed significance $(P<0.001)$ for all traits except 1000 seeds weight. The results of factors' interaction showed that entries by planting dates and entries by sites were significant $(P<0.001)$ for all traits except 1000 seeds weight. On the other hand, entries by planting dates and those by sites were significant $(P<0.001)$ for grain yield, panicles weight, and midge damage (Table 1).

In the first planting date at Konni, entries were highly significant $(P<0.001)$ for grain yield, plant height, panicles weight, and midge damage, while significant differences $(P<$ 0.005 ) were observed for days to $50 \%$ flowering and 1000 seeds weight (Table 2).

In the second planting date at Konni, the entries were highly significant $(P<0.001)$ for all characters under study except midge damage which was significant at $5 \%$ level (Table 3).

The combined analyses of variance over the two planting dates at Konni reveal that entries were significant at $1 \%$ level for all characters except 1000 seed weight which was 
TABLE 3: Mean squares for traits in the second planting date at Konni.

\begin{tabular}{lccccccc}
\hline Source of variation & d.f. & GY & PH & PW & FF & TSW & MD \\
\hline Replications & 1 & 108631 & 24239 & 1612 & 456.41 & 4.43 & 0.40335 \\
Entries & 281 & $264307^{* *}$ & $2706^{* *}$ & $2336^{* *}$ & $91.41^{* *}$ & $85.07^{* *}$ & $0.11681^{*}$ \\
Residual & 281 & 138467 & 1001 & 1138 & 57.52 & 29.6 & 0.07664 \\
CV & & 61.8 & 16.7 & 48.8 & 10.5 & 23.8 & 43.2 \\
\hline
\end{tabular}

GY: grain yield; PH: plant height; PW: panicle weight; FF: days to $50 \%$ flowering; TSW: 1000 seeds weight; MD: midge damage; ns: not significant; ${ }^{*}$ significant at $1 \% ;{ }^{*}$ significant at $5 \%$.

TABLE 4: Mean squares for traits across planting dates at Konni.

\begin{tabular}{|c|c|c|c|c|c|c|c|}
\hline Source of variation & d.f. & GY & $\mathrm{PH}$ & PW & FF & TSW & $\mathrm{MD}$ \\
\hline Replications & 1 & 2514949 & 8312.6 & 6006.4 & 298.54 & 8.9 & 1.90569 \\
\hline Entries & 281 & $196938^{* *}$ & $5738^{* *}$ & $2476.2^{* *}$ & $122.73^{* *}$ & $144.7^{*}$ & $0.1662^{* *}$ \\
\hline PD & 1 & $353779^{*}$ & $804414.1^{* *}$ & $3276.3^{*}$ & $436.87^{*}$ & $5832.9^{* *}$ & $7.98005^{* *}$ \\
\hline Entries.PD & 281 & $166350^{* *}$ & $1259^{* *}$ & $1373.4^{* *}$ & $65.26^{*}$ & $127.7^{*}$ & $0.13463^{* *}$ \\
\hline Residual & 563 & 92645 & 817.1 & 827 & 70.83 & 121 & 0.07053 \\
\hline $\mathrm{CV}$ & & 61.4 & 13.2 & 41.0 & 11.7 & 33.4 & 49.0 \\
\hline
\end{tabular}

GY: grain yield; PH: plant height; PW: panicle weight; FF: days to 50\% flowering; TSW: 1000 seeds weight; MD: midge damage; PD: planting dates; ns: not significant; ${ }^{*}$ significant at $1 \% ;{ }^{* *}$ significant at $5 \%$.

TABLE 5: Mean squares for traits in the first planting date at Maradi.

\begin{tabular}{lccccccc}
\hline Source of variation & d.f. & GY & PH & PW & FF & TSW & MD \\
\hline Replications & 1 & 145655 & 20840.5 & 10054 & 26.9 & 346.56 & 0.03682 \\
Entries & 281 & $71434^{* *}$ & $3253.8^{* *}$ & $3458^{* *}$ & $85.22^{* *}$ & $22.98^{* *}$ & $0.007987^{\text {ns }}$ \\
Residual & 281 & 39197 & 840.2 & 1750 & 18.86 & 14.12 & 0.009737 \\
CV & & 54.0 & 15.7 & 30.3 & 6.4 & 18.4 & 33.6 \\
\hline
\end{tabular}

GY: grain yield; PH: plant height; PW: panicle weight; FF: days to 50\% flowering; TSW: 1000 seeds weight; MD: midge damage; ns: not significant; ${ }^{*}$ significant at $1 \% ;{ }^{*}$ significant at $5 \%$.

TABLE 6: Mean squares for traits in the second planting date at Maradi.

\begin{tabular}{|c|c|c|c|c|c|c|c|}
\hline Source of variation & d.f. & GY & $\mathrm{PH}$ & PW & FF & TSW & $\mathrm{MD}$ \\
\hline Replications & 1 & 316788 & 145.3 & 84656 & 1.95 & 5.1 & 0.27202 \\
\hline Entries & 281 & $44959^{* *}$ & $2655.2^{* *}$ & $4019^{* *}$ & $6.61^{\mathrm{ns}}$ & $32.9^{* *}$ & $0.13734^{*}$ \\
\hline Residual & 281 & 21581 & 827.9 & 2532 & 7.81 & 22.19 & 0.09183 \\
\hline $\mathrm{CV}$ & & 52.6 & 20.3 & 34.5 & 26.7 & 23.8 & 49.1 \\
\hline
\end{tabular}

GY: grain yield; PH: plant height; PW: panicle weight; FF: days to $50 \%$ flowering; TSW: 1000 seeds weight; MD: midge damage; ns: not significant; ${ }^{*}$ significant at $1 \% ;{ }^{* *}$ significant at $5 \%$.

significant at 5\% level. Planting dates were significant at $1 \%$ level for plant height, 1000 seeds weight, and midge damage, while grain yield, panicle weight, and days to $50 \%$ flowering were significant at $5 \%$ level. The interaction of planting dates and entries was significant at $1 \%$ level for all characters except days to $50 \%$ flowering and 100 seed weight which were significant at 5\% level (Table 4).

In the first planting date at Maradi, entries were highly significant $(P<0.001)$ for all characters under study except midge damage (Table 5).

In the second planting date at Maradi, entries were highly significant $(P<0.001)$ for grain yield, plant height, panicle weight, and 1000 seeds weight were significant $(P<0.005)$ for midge damage. There were no significant differences in the genotypes for days to $50 \%$ flowering (Table 6).
The combined analyses of variance over the two planting dates at Maradi show that entries were highly significant for all characters under study $(P<0.001)$. Planting dates were highly significant $(P<0.001)$ for grain yield, plant height, panicles weight, and midge damage; significant differences $(P<0.005)$ were observed for days to $50 \%$ flowering and 1000 seeds weight. The interaction of entries and planting dates was highly significant $(P<0.001)$ for grain yield and midge damage and significantly different $(P<0.005)$ for plant height, panicle weight, days to $50 \%$ flowering, and 1000 seeds weight (Table 7).

3.2. Estimates of Coefficients of Variation, Heritability, and Genetic Advance. Across environments, the GCV values range from $6.64 \%$ for days to $50 \%$ flowering to $31.37 \%$ for 
TABLE 7: Mean squares for traits across planting dates at Maradi.

\begin{tabular}{lccccccc}
\hline Source of variation & d.f. & GY & PH & PW & FF & TSW & MD \\
\hline Replications & 1 & 1071 & 10381.4 & 9380 & 298.54 & 134.47 \\
Entries & 281 & $78655^{* *}$ & $4854.7^{* *}$ & $5051^{* *}$ & $122.73^{* *}$ & $37.86^{* *}$ & 0.02 \\
PD & 1 & $9165215^{* *}$ & $506918.5^{* *}$ & $579791^{* *}$ & $436.87^{*}$ & $142.93^{*}$ & $52.52^{* *}$ \\
Entries.PD & 281 & $50070^{* *}$ & $1128.6^{*}$ & $3033^{*}$ & $65.26^{*}$ & $17.92^{*}$ & $0.07^{* *}$ \\
Residual & 563 & 32323 & 854.5 & 2213 & 70.83 & 18.51 & 0.04 \\
CV & & 65.5 & 17.9 & 40.9 & 8.3 & 21.4 & 44.3 \\
\hline
\end{tabular}

GY: grain yield; PH: plant height; PW: panicle weight; FF: days to 50\% flowering; TSW: 1000 seeds weight; MD: midge damage; ns: not significant; ${ }^{*}$ significant at $1 \% ;{ }^{* *}$ significant at $5 \%$.

TABLE 8: Genetic variation for resistance to midge, yield, and yield contributing characters for the combined environments.

\begin{tabular}{|c|c|c|c|c|c|c|c|}
\hline Traits & GM & GV & PV & GCV (\%) & PCV (\%) & $H_{\mathrm{BS}}(\%)$ & $\mathrm{GA}$ as $\%$ of mean \\
\hline GY & 382,4 & 14386,38 & 22172,13 & 31,37 & 38,94 & 65.58 & 50.63 \\
\hline $\mathrm{PH}$ & 189,99 & 1091,63 & 1198,18 & 17,39 & 18,22 & 91.41 & 33.28 \\
\hline PW & 92,44 & 413,50 & 606,00 & 22,00 & 26,63 & 68.38 & 36.41 \\
\hline $\mathrm{FF}$ & 69,47 & 21,25 & 27,49 & 6,64 & 7,55 & 77.28 & 11.75 \\
\hline TSW & 20,34 & 4,77 & 12,83 & 10,74 & 17,61 & 37.12 & 13.17 \\
\hline $\mathrm{MD}$ & 0,34 & 0,01 & 0,02 & 30,91 & 39,52 & 61.62 & 49.34 \\
\hline
\end{tabular}

GY: grain yield; PH: plant height; PW: panicle weight; FF: days to 50\% flowering; TSW: 1000 seeds weight; MD: midge damage; GM: grand mean; GV: genotypic variance; PV: phenotypic variance; GCV: genotypic coefficient of variance; PCV: phenotypic coefficient of variance; $H_{(\mathrm{BS})}$ : broad sense heritability; GA: genetic advance as a percentage of mean.

TABLE 9: Genetic variation for resistance to midge, yield, and yield contributing characters in the first planting date at Konni.

\begin{tabular}{|c|c|c|c|c|c|c|c|}
\hline Traits & GM & GV & PV & PCV (\%) & GCV (\%) & $H_{(\mathrm{BS})}(\%)$ & GA (\% mean) \\
\hline GY & 479 & 17481 & 83856 & 59.09 & 26.98 & 20.84 & 24.90 \\
\hline $\mathrm{PH}$ & 243.4 & 1811.45 & 2459.35 & 20.37 & 17.48 & 73.65 & 30.63 \\
\hline PW & 71.7 & 404.1 & 1047.7 & 45.14 & 28.03 & 38.57 & 35.33 \\
\hline FF & 71.25 & 7.85 & 87.62 & 13.13 & 3.93 & 8.95 & 21.65 \\
\hline TSW & 18.3 & 2.85 & 92.45 & 52.54 & 9.22 & 3.08 & 31.25 \\
\hline MD & 0.37 & 0.03 & 0.10 & 86.94 & 52.64 & 36.66 & 64.47 \\
\hline
\end{tabular}

GY: grain yield; PH: plant height; PW: panicle weight; FF: days to 50\% flowering; TSW: 1000 seeds weight; MD: midge damage; GM: grand mean; GV: genotypic variance; PV: phenotypic variance; GCV: genotypic coefficient of variance; PCV: phenotypic coefficient of variance; $H_{(B)}$ : broad sense heritability; GA: genetic advance as a percentage of mean.

grain yield. Grain yield, panicles weight, and midge damage recorded high GCV value. Plant height and 1000 seeds weight recorded medium GCV value, while days to $50 \%$ flowering recorded low GCV value. The PCV values range from $7.55 \%$ for days to $50 \%$ flowering to $39.52 \%$ for midge damage. Midge damage, grain yield, and panicles weight recorded high PCV value. Plant height and 1000 seeds weight recorded medium PCV value, while days to 50\% flowering recorded low PCV value (Table 8). Heritability estimates ranged from $91.41 \%$ for plant height to $37.12 \%$ for 1000 seeds weight. All traits recorded high heritability estimates (Table 8). The estimates of genetic advance as percentage of mean ranged from $50.63 \%$ for grain yield to $11.75 \%$ for days to $50 \%$ flowering. Grain yield, plant height, panicles weight, and midge damage displayed high genetic advance as percentage of mean, while days to $50 \%$ flowering and 1000 seeds weight displayed medium genetic advance as a percentage of mean (Table 8).
In the first planting date at Konni, GCV ranged from $52.64 \%$ for midge damage to $3.93 \%$ for days to flowering. Midge damage, panicle weight, and grain yield showed high GCV, plant height recorded medium GCV, and days to $50 \%$ flowering had low GCV. On the other hand, PCV values ranged from $86.94 \%$ for midge damage to $13.13 \%$ for days to $50 \%$ flowering. Midge damage, grain yield, plant height, and panicle weight exhibited high PCV, while days to $50 \%$ flowering displayed medium PCV (Table 9). Heritability estimates ranged from $73.65 \%$ for plant height to $8.57 \%$ for days to $50 \%$ flowering. Days to $50 \%$ flowering exhibited low heritability, while midge damage, panicle weight, plant height, and grain yield showed high heritability estimates. The highest estimate of genetic advance was seen for midge damage (64.47\%) and the lowest estimate was for days to $50 \%$ flowering (Table 9).

In the second planting date at Konni, GCV ranged from $48.42 \%$ for grain yield to $5.65 \%$ for days to flowering. Midge 
TABLE 10: Genetic variation for resistance to midge, yield, and yield contributing characters in the second planting date at Konni.

\begin{tabular}{|c|c|c|c|c|c|c|c|}
\hline Traits & GM & $\mathrm{GV}$ & $\mathrm{PV}$ & PCV (\%) & GCV (\%) & $H_{(\mathrm{BS})}(\%)$ & GA ( $\%$ mean $)$ \\
\hline GY & 518 & 62920 & 201387 & 86.63 & 48.42 & 31.24 & 55.32 \\
\hline $\mathrm{PH}$ & 189.3 & 852.5 & 1853.5 & 22.74 & 15.42 & 45.99 & 21.08 \\
\hline PW & 69.2 & 599 & 1737 & 60.22 & 35.36 & 34.48 & 42.18 \\
\hline $\mathrm{FF}$ & 72.53 & 16.94 & 74.46 & 11.89 & 5.67 & 22.75 & 5.39 \\
\hline TSW & 22.89 & 27.73 & 57.33 & 33.07 & 23.00 & 48.37 & 32.70 \\
\hline MD & 0.52 & 0.02 & 0.09 & 59.80 & 27.25 & 20.76 & 24.64 \\
\hline
\end{tabular}

GY: grain yield; PH: plant height; PW: panicle weight; FF: days to 50\% flowering; TSW: 1000 seeds weight; MD: midge damage; GM: grand mean; GV: genotypic variance; PV: phenotypic variance; GCV: genotypic coefficient of variance; PCV: phenotypic coefficient of variance; $H_{(\mathrm{BS})}$ : broad sense heritability; GA: genetic advance as a percentage of mean.

TABLE 11: Genetic variability for resistance to midge, yield, and yield contributing characters across planting dates at Konni.

\begin{tabular}{|c|c|c|c|c|c|c|c|}
\hline Traits & GM & GV & $\mathrm{PV}$ & PCV (\%) & GCV (\%) & $H_{(\mathrm{BS})}(\%)$ & GA (\% mean) \\
\hline GY & 495.5 & 52146.5 & 144791.5 & 76.79 & 46.08 & 36.01 & 56.95 \\
\hline $\mathrm{PH}$ & 216.49 & 2460.45 & 3277.55 & 26.44 & 32.40 & 75.06 & 40.85 \\
\hline PW & 70.11 & 551.4 & 1378.4 & 52.95 & 47.36 & 40.00 & 43.63 \\
\hline $\mathrm{FF}$ & 71.88 & 25.95 & 96.78 & 13.68 & 10.02 & 26.81 & 7.33 \\
\hline TSW & 20.59 & 11.85 & 132.85 & 55.97 & 23.64 & 8.91 & 9.22 \\
\hline $\mathrm{MD}$ & 0.45 & 0.04 & 0.11 & 76.45 & 68.73 & 40.41 & 62.99 \\
\hline
\end{tabular}

GY: grain yield; PH: plant height; PW: panicle weight; FF: days to 50\% flowering; TSW: 1000 seeds weight; MD: midge damage; GM: grand mean; GV: genotypic variance; PV: phenotypic variance; GCV: genotypic coefficient of variance; PCV: phenotypic coefficient of variance; $H_{(\mathrm{BS})}$ : broad sense heritability; GA: genetic advance as a percentage of mean.

damage, 1000 seeds weight, panicle weight, and grain yield had high GCV, plant height had medium GCV, and days to $50 \%$ flowering had low GCV. On the other hand, the PCV estimates ranged from $86.63 \%$ for grain yield to $11.89 \%$ for days to flowering. All characters exhibited high PCV except days to $50 \%$ flowering which was medium. Heritability estimates ranged from $48.37 \%$ for 1000 seeds weight to $20.76 \%$ for midge damage. All characters under study exhibited relatively high heritability estimates (Table 10). The estimates of genetic advance as a percentage of the mean ranged from 55.32\% for grain yield to $5.39 \%$ for days to $50 \%$ flowering. The high estimates $(>20 \%)$ were recorded by grain yield $(55.32 \%)$, panicle weight (42.18\%), 1000 seeds weight $32.70 \%$, midge damage $(24.64 \%)$, and plant height $(21.08 \%)$. Low $(<10 \%)$ GA estimate was recorded by days to $50 \%$ flowering $(5.39 \%)$ (Table 10).

The estimates for GCV ranged from $68.73 \%$ for midge damage to $47.36 \%$ for panicle weight, while the PCV ranged from $76.79 \%$ for grain yield to $13.68 \%$ for days to $50 \%$ flowering. Grain yield, plant height, panicle weight, 1000 seeds weight, and midge damage recorded high PCV values, while days to $50 \%$ flowering recorded medium PCV values. On the other hand, grain yield, plant height, panicle weight, 1000 seeds weight, and midge damage showed high GCV values, whereas days to $50 \%$ flowering had a low GCV value (Table 11). The estimates of heritability ranged from $75.06 \%$ for plant height to $8.91 \%$ for 1000 seeds weight. Grain yield, plant height, panicle weight, and midge damage exhibited high heritability estimates, days to $50 \%$ flowering recorded medium heritability, and the heritability of 1000 seeds weight was low. Hence, good progress in selection could be obtained for these characters if used as selection criteria (Table 11). High GA estimates (>20\%) were recorded for midge damage (62.99\%), grain yield (56.95\%), panicle weight $(43.63 \%)$, and plant height (40.85\%). Days to $50 \%$ flowering and 1000 seeds weight had low GA estimates with $7.33 \%$ and $9.22 \%$, respectively (Table 11).

In the first planting date at Maradi, GCV ranged from $34.65 \%$ for grain yield to $8.55 \%$ for days to $50 \%$ flowering, while the PCV ranges from $64.26 \%$ for grain yield to $10.71 \%$ for days to flowering. All characters had high GCV except days to $50 \%$ flowering which had a low GCV value. All characters exhibited high PCV values except days to $50 \%$ flowering which had medium values (Table 12). Heritability ranged from $58.95 \%$ for plant height to $23.88 \%$ for 1000 seeds weight. All characters displayed high heritability in the present study. High $(>20 \%)$ genetic advance as percentage of mean was detected for grain yield (38.34\%), plant height (29.33\%), and panicle weight (24.39\%). Medium (10-20\%) genetic advance was detected for days to $50 \%$ flowering $(13.90 \%)$ and the low $(<10 \%)$ genetic advance was for 1000 seeds weight (9.96\%) (Table 12).

In the second planting date at Maradi, GCV ranged from $58.56 \%$ for grain yield to $11.71 \%$ for 1000 seeds weight, while PCV ranged from $98.80 \%$ for grain yield to $26.57 \%$ for 1000 seeds weight. All characters showed high GCV except 1000 seeds weight which showed medium GCV, while all characters displayed high PCV values (Table 13). The heritability ranged from $35.13 \%$ for grain yield to $19.85 \%$ for 1000 seeds weight. Grain yield, plant height, and panicle weight had high heritability estimates, while 1000 seeds weight and midge damage had medium heritability estimates. High (>20\%) 
TABLE 12: Genetic variation for resistance to midge, yield, and yield contributing characters in the first planting date at Maradi.

\begin{tabular}{|c|c|c|c|c|c|c|c|}
\hline Traits & GM & GV & PV & PCV (\%) & GCV (\%) & $H_{(\mathrm{BS})}(\%)$ & GA (\% mean) \\
\hline GY & 366.4 & 16118.5 & 55315.5 & 64.26 & 34.65 & 29.13 & 38.34 \\
\hline $\mathrm{PH}$ & 184.3 & 1206.8 & 2047 & 24.54 & 18.84 & 58.95 & 29.33 \\
\hline PW & 137.9 & 854 & 2604 & 37.00 & 21.19 & 32.79 & 24.39 \\
\hline FF & 67.34 & 33.18 & 52.04 & 10.71 & 8.55 & 63.75 & 13.90 \\
\hline TSW & 20.47 & 4.43 & 18.55 & 21.04 & 10.28 & 23.88 & 9.96 \\
\hline
\end{tabular}

GY: grain yield; PH: plant height; PW: panicle weight; FF: days to 50\% flowering; TSW: 1000 seeds weight; GM: grand mean; GV: genotypic variance; PV: phenotypic variance; GCV: genotypic coefficient of variance; PCV: phenotypic coefficient of variance; $H_{(\mathrm{BS})}$ : broad sense heritability; GA: genetic advance as a percentage of mean.

TABLE 13: Genetic variation for resistance to midge, yield, and yield contributing characters in the second planting date at Maradi.

\begin{tabular}{lccccccc}
\hline Traits & GM & GV & PV & PCV (\%) & GCV (\%) & $H_{(\mathrm{BS})}(\%)$ & GA (\% mean) \\
\hline GY & 184.6 & 11689 & 33270 & 98.80 & 58.56 & 21.31 & 52.46 \\
PH & 141.8 & 913.65 & 1741.55 & 29.43 & 29.54 & 22.69 & 31.24 \\
PW & 92.3 & 743.5 & 3275.5 & 62.00 & 11.71 & 19.44 & 28.10 \\
TSW & 19.75 & 5.355 & 27.54 & 26.57 & 35.08 & 19.85 \\
MD & 0.43 & 0.02 & 0.11 & 78.72 & 30.40 \\
\hline
\end{tabular}

GY: grain yield; PH: plant height; PW: panicle weight; FF: days to 50\% flowering; TSW: 1000 seeds weight; MD: midge damage; GM: grand mean; GV: genotypic variance; PV: phenotypic variance; GCV: genotypic coefficient of variance; PCV: phenotypic coefficient of variance; $H_{(\mathrm{BS})}$ : broad sense heritability; GA: genetic advance as a percentage of mean.

TABLE 14: Genetic variation for resistance to midge, yield, and yield contributing characters across planting dates at Maradi.

\begin{tabular}{|c|c|c|c|c|c|c|c|}
\hline Traits & GM & GV & PV & PCV (\%) & GCV (\%) & $H_{(\mathrm{BS})}(\%)$ & GA (\% mean) \\
\hline GY & 274.7 & 23166 & 55489 & 47.54 & 30.71 & 41.74 & 72.42 \\
\hline $\mathrm{PH}$ & 163.02 & 2000.1 & 2854.6 & 24.67 & 29.21 & 70.06 & 47.26 \\
\hline PW & 115.1 & 1009 & 3222 & 80.96 & 64.07 & 31.31 & 31.49 \\
\hline $\mathrm{FF}$ & 67.12 & 25.95 & 96.78 & 13.68 & 10.02 & 26.81 & 7.85 \\
\hline TSW & 20.13 & 9.67 & 28.18 & 25.78 & 21.36 & 34.32 & 18.47 \\
\hline $\mathrm{MD}$ & 0.22 & 0.01 & 0.05 & 111.12 & 79.59 & 25.64 & 57.23 \\
\hline
\end{tabular}

GY: grain yield; PH: plant height; PW: panicle weight; FF: days to 50\% flowering; TSW: 1000 seeds weight; MD: midge damage; GM: grand mean; GV: genotypic variance; PV: phenotypic variance; GCV: genotypic coefficient of variance; PCV: phenotypic coefficient of variance; $H_{(B)}$ : broad sense heritability; GA: genetic advance as a percentage of mean.

estimates of genetic advance as percentage of mean were seen for grain yield (71.24\%), plant height $(31.52 \%)$, midge damage (30.81\%), and panicle weight (28.10\%). Medium (10-20\%) estimate of GA was seen for 1000 seeds weight (10.40\%) (Table 13).

Across planting date, high GCV was recorded for midge damage, panicle weight, grain yield, plant height, and 1000 seeds weight across planting dates at Maradi. Days to 50\% flowering recorded lower GCV. Panicle weight, grain yield, plant height, and 1000 seeds weight had high PCV, while days to $50 \%$ flowering had medium PCV (Table 14). The highest heritability was seen for plant height $(70.06 \%)$ and the lowest heritability for midge damage $(25.64 \%)$. All characters under study exhibited relatively high heritability. High estimates of GA (>20\%) were seen for grain yield $(72.42 \%)$, midge damage (57.23\%), plant height (47.26\%), and panicle weight $(31.40 \%)$. Low $(<10 \%)$ estimates of genetic advance as percentage of mean were seen for days to $50 \%$ flowering (7.85\%), while medium (10-20\%) GA was seen for 1000 seeds weight (Table 14).

\section{Discussion}

Across environments, entries, planting dates, and interaction between planting dates and sites contributed to the variations observed. However, sites and the interaction of entries by sites and entries by planting dates contributed to the variations for all except 1000 seeds weight. Entries by sites and those by planting dates contributed to the variations observed for grain yield, panicles weight, and midge damage. Therefore selection could be accomplished for grain yield, panicles weight, and resistance to midge across the study environments.

At Konni, differences due to entries, planting dates, and entries by planting dates interactions across planting dates indicate that planting date and genotypes played an important role in the genetic variation observed. Likewise, at Maradi, significant variation was observed across the two planting dates for all characters among genotypes, planting dates, and genotypes by planting dates. This shows that entries, planting dates, and entries by planting dates interactions contributed 
to the genetic variation observed in all the characters under study. Hence, selection for improving these characters in sorghum could be achieved in either of the two planting dates at Maradi.

In the first planting date, entries at Konni contributed to the genetic variation found in all characters, while at Maradi, in the first planting date, entries displayed differences for all characters except midge damage. Therefore, breeding for improving grain yield, plant height, panicle weight, days to $50 \%$ flowering, and 1000 seeds weight in sorghum for early planting through selection among the entries could be successful at both study sites, whereas selection for resistance to sorghum midge can only be achieved in the first planting date at Konni.

In the second planting date at Konni, entries contributed to the general genetic variability observed for all characters including resistance to sorghum midge. Selection can be attained for improving sorghum for these characters for use in late planting. In the second planting date at Maradi, genotypes were different for all characters except days to $50 \%$ flowering. Hence, selection can be achieved for grain yield, plant height, panicle weight, 1000 seeds weight, and resistance to midge in late planting sorghum at Maradi.

In general, phenotypic coefficient of variation was greater than the genotypic coefficient of variation for all the characters in the first planting and second planting dates at all locations. This suggests environment influences on the expression of these characters. Since PCV estimates the effects of genotypes and environment, higher PCV versus GCV indicates a significant contribution of environment and genotypes by environment interaction in the expression of all characters in both sites as well as planting dates. Similar results on cultivated sorghum were reported by Bello et al. [7] in Nigeria. References $[19,20]$ also found similar results for quantitative characters in sorghum.

The existence of high GCV in the present study suggests that selection for characters across planting dates at Konni and Maradi as well as across environments should be possible. Selection could be done for all characters except days to $50 \%$ flowering across environments and in both planting dates at Konni. At Maradi, selection could be done for grain yield, plant height, panicle weight, and 1000 seeds weight in the first planting date, while in the second planting date, selection can be successful for all characters except days to $50 \%$ flowering.

The coefficient of variation only indicates the extent of total variability present for a character and does not split the variability into heritable and nonheritable portions as reported [21, 22]. Hence, the determination of the heritability appears to be of great importance. In the present investigations, high heritability was seen for almost all the characters. Across environments, the broad sense heritability estimates were high for all traits. At Konni and Maradi, except days to $50 \%$ flowering at Konni, broad sense heritability estimates were high for all characters across planting dates. The high heritability observed for these characters indicates that genotype plays more important role than environment in determining the phenotype, suggesting the predominance of both additive and dominant gene effects in the inheritance of the characters.
In the first planting date at Konni, except for days to $50 \%$ flowering and 1000 seeds weight, all characters displayed high heritability at both sites. In the second planting date, all characters showed high broad sense heritability estimates. At Maradi, grain yield, plant height, and panicle weight displayed high heritability, while 1000 seeds weight and midge damage had medium heritability. Since high heritability estimates were observed for these characters, the contribution of the genotype was higher than that of environment to determining the phenotype. Therefore, additive and dominant gene effects probably were important in the inheritance of grain yield, plant height, panicle weight, and resistance to midge in the first planting date at Konni and for all characters at Maradi for the first planting date. Therefore, genotypes could be selected based on phenotype for improving sorghum for grain yield, plant height, panicle weight, and resistance to midge for early planting at Konni and for all the characters at Maradi.

Likewise, in the second planting date at Konni, genotype contributed to the expression of all characters, suggesting that additive and dominant gene effects are important for all characters in the second planting date at Konni. Hence, in the second planting date at Konni, entries could be selected based on phenotype for improving all characters under study.

However, in the second planting date at Maradi, genotypes contributed to the inheritance of grain yield, plant height, and panicle weight. Therefore, genotypes could be selected based on phenotype for improving grain yield, plant height, and panicle weight. High heritability for grain yield per panicle and plant height and moderate heritability for days to $50 \%$ flowering were documented by Chavan et al. [23], while Sharma et al. [24] found high heritability for number of grains per panicle and plant height.

Across all the study environments and across planting dates at both Konni and Maradi, grain yield, plant height, panicle weight, and midge damage had high heritability estimates coupled with high estimates of genetic advance. Hence, selection would be effective for these characters across planting dates at both Konni and Maradi as well as across the study environments.

At Konni, in both planting dates, all characters displayed high estimates of GA coupled with high heritability except days to $50 \%$ flowering. Hence, selection might be successful for grain yield, plant height, panicle weight, and resistance to midge for early planting materials at Konni as well as late planting date.

At Maradi, grain yield, plant height, and panicle weight showed high estimates of GA coupled with high heritability estimates in both planting dates. Therefore, selection might be successful for grain yield, plant height, and panicle weight for either early or late planting dates.

Investigation of genetic variability in sorghum by Chavan et al. [23] revealed high estimates of GA coupled with high heritability for number of grains per panicle, plant height, and grain yield per panicle, whereas high heritability and low estimates of genetic advance were identified for panicle width, panicle length, and test weight. Similar results were obtained by Bapat and Shinde [25]. High estimates of genetic advance for days to $50 \%$ flowering were documented by Kishor and 
Singh [26]. High heritability coupled with high GA for plant height and grain yield was reported by Dabholkar [27]. Evidence of heritability coupled with high GA for yield and yield components in rabi sorghum was provided by Arunkumar et al. [28].

\section{Conclusion}

Variations were observed among landrace-derived sorghum lines for sorghum midge resistance, yield, and yield related traits in the two experimental sites and the two different planting dates within the sites. The results of this study suggest a way of improving sorghum by selecting for yield, yield contributing traits, and resistance to sorghum midge using landrace-derived germplasm in Niger. Across planting dates, at both Konni and Maradi, grain yield, plant height, panicle weight, and midge damage had high heritability estimates coupled with high estimates of genetic advance. At Konni in both planting dates, all characters displayed high heritability estimates coupled with high GA except days to $50 \%$ flowering. At Maradi, grain yield, plant height, and panicle weight had high heritability coupled with high GA in both planting dates. Therefore, there is evidence that breeding for resistance to sorghum midge can be obtained in addition to other traditional breeding objectives such as yield and yield contributing traits at Konni, whereas breeding for midge resistance may not be successful at Maradi.

\section{Disclosure}

This work has been undertaken as part of the CGIAR Research Program on Dryland Cereals.

\section{Conflicts of Interest}

The authors declare that they have no conflicts of interest.

\section{Acknowledgments}

The authors wish to acknowledge Alliance for a Green Revolution in Africa (AGRA) for funding this work and the West Africa Centre for Crop Improvement (WACCI) for the good training.

\section{References}

[1] FAOSTAT, Statistical Yearbook 2013: World Food and Agriculture, Organziation UN, Rome, Italy, 2014, http://faostat.fao.org/ site/291/default.aspx.

[2] H. A. Kadi Kadi, I. Kapran, and B. B. Pendleton, "Identification of sorghum genotypes resistant to sorghum midge in Niger," International Sorghum And Millets Newsletter, 2005.

[3] N. Maman, S. C. Mason, D. J. Lyon, and P. Dhungana, "Yield components of pearl millet and grain sorghum across environments in the central Great Plains," Crop Science, vol. 44, no. 6, pp. 2138-2145, 2004.

[4] S. S. Mary and A. Gopalan, "Dissection of genetic attributes yield traits of fodder cowpea in F3 and F4," Journal of Applied Sceneces Research, vol. 2, pp. 805-808, 2006.
[5] S. Q. Ahmad, S. Khan, M. Ghaffar, and F. Ahmad, "Genetic diversity analysis for yield and other parameters in maize (Zea mays L.) genotypes," Asian Journal of Agricultural Sciences, vol. 3, no. 5, pp. 385-388, 2011.

[6] R. A. Sami, M. Y. Yeye, M. F. Ishiyaku, and I. S. Usman, "Heritability studies in some sweet sorghum (Sorghum Bicolor. L. Moench) genotypes," Journal of Biology Agriculture and Healthcare, vol. 3, no. 17, pp. 49-51, 2013.

[7] D. Bello, A. M. Kadams, S. Y. Simon, and D. S. Mashi, "Studies on genetic variability in cultivated sorghum (Sorghum bicolor L. Moench) cultivars of Adamawa State Nigeria," AmericanEuriasian Journal Agricultural Enviroment Science, vol. 2, no. 3, pp. 297-302, 2007.

[8] Y. N. Warkad, N. R. Potdukhe, A. M. Dethe, P. A. Kahate, and R. R. Kotgire, "Genetic variability, heritability and genetic advance for quantitative traits in sorghum germplasm," Agricultural Science Digest, vol. 28, no. 3, pp. 165-169, 2008.

[9] R. R. Dhutmal, S. P. Mehetre, A. W. More, H. V. Kalpande, A. G. Mundhe, and A. J. Sayyad Abubakkar, "Variabity parameters in rabi sorghum (sorghum bicolor L. Moench) drought tolerent genotypes," The Bio-Scan, vol. 9, no. 4, pp. 1455-1458, 2014.

[10] M. Q. Khan, S. I. Awan, and M. M. Mughal, "Estimation of genetic parameters in spring wheat genotypes under rainfed conditions," Industrial Journal of Biological Sciences, vol. 2, no. 3, pp. 367-370, 2005.

[11] W.-U. Haq, M. F. Malik, M. Rashid, M. Munir, and Z. Akram, "Evaluation and estimation of heritability and genetic advancement for yield related attributes in wheat lines," Pakistan Journal of Botany, vol. 40, no. 4, pp. 1699-1702, 2008.

[12] D. S. Falconer and T. F. C. Mackay, Introduction to Quantitative Genetics, Benjamin Cummings, England, 4th edition, 1996.

[13] S. O. F. I. Najeeb, A. G. Rather, G. A. Parray, F. A. Sheikh, and S. M. Razvi, "Studies on genetic variability, genotypic correlation and path coefficient analysis in maize under the high altitude temperate conditions of Kashmir," Maize Genetics Cooperation Newsletter, vol. 83, pp. 1-8, 2009.

[14] C. M. Rafiq, M. Rafique, A. Hussain, and M. Altaf, "Studies on heritability, correlation and path analysis in maize (Zea mays L.)," Journal of Agricultural Research, vol. 48, no. 1, pp. 35-38, 2010.

[15] B. M. Atta, M. A. Haq, and T. M. Shah, "Variation and interrelationships of quantitative traits in chickpea (Cicer arietinum L.)," Pakistan Journal of Botany, vol. 40, no. 2, pp. 637-647, 2008.

[16] C. H. Hanson, H. F. Robinson, and R. E. Comstock, "Biometrical studies in yield of segregating population of Korean lespediza," Agronomy Journal, vol. 48, pp. 214-318, 1956.

[17] G. W. Burton, "Quantitative inheritance in grasses," in Proceedings of the 6th International Grassland Congress, 1, pp. 277-283, USA, 1952.

[18] H. W. Johonson, H. F. Robinson, and R. E. Comostock, "Genotypic and phenotypic correlations in soybeans and their implication in selection," Agronomy Journal, vol. 47, pp. 477-483, 1955.

[19] A. K. Basu, "Variability and heritability estimate from interseason sorghum cross," Indian Journal of Agricultural Sciences, vol. 41, pp. 116-117, 1981.

[20] E. H. Abu-Gasim and A. E. Kambal, "Variability and interrelationship among characters in indigenous grain sorghum of the Sudan," Crop Science, vol. 11, pp. 308-309, 1985.

[21] D. Lakshmana, B. D. Biradar, and R. L. R. kumar, "Genetic variability studies for quantitative traits in a pool of restorers 
and maintainers lines of pearl millet (Pennisetum glaucum (L.))," Karnataka Journal of Agricultural Science, vol. 22, pp. 881882, 2009.

[22] M. Govindaraj, B. Selvi, S. Rajarathinam, and P. Sumathi, "Genetic variability and heritability of grain yield components and grain mineral concentration in India's pearl millet (Pennietum glaucum (L) R. Br.) accessions," African Journal of Food, Agriculture, Nutrition and Development, vol. 11, no. 3, 2011.

[23] S. K. Chavan, R. C. Mahajan, and S. U. Fatak, "Genetic variability studies in sorghum," Karnataka Journal of Agricultural Sciences, vol. 23, pp. 322-323, 2010.

[24] H. Sharma, D. K. Jain, and V. Sharma, "Genetic variability and path coefficient analysis in sorghum," Indian Journal of Agricultural Research, vol. 40, pp. 310-312, 2006.

[25] D. R. Bapat and M. D. Shinde, "Study of genetic variability for grain yield in sorghum," Sorghum Newsltr, vol. 23, pp. 27-28, 1980.

[26] N. Kishor and L. N. Singh, "Variability and association studies under irrigated and rainfed situations in the sub-montane region in forage sorghum," Crop Research, vol. 29, no. 2, pp. 252258, 2005.

[27] A. R. Dabholkar, Element of Biometrical Genetics, Concept Publishing Company, New Delhi, India, 1992.

[28] B. Arunkumar, B. D. Biradar, and P. M. Salimath, "Genetic variability and character association studies in rabi sorghum," Karnataka Jornal of Agricultural Science, vol. 17, pp. 471-475, 2004. 


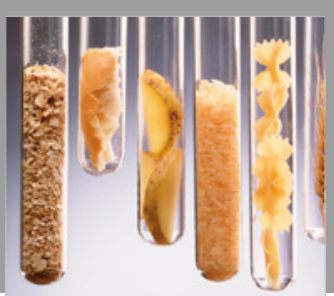

International Journal of Food Science

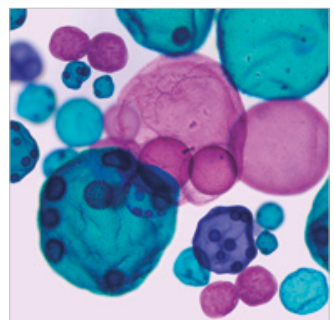

International Journal of Microbiology
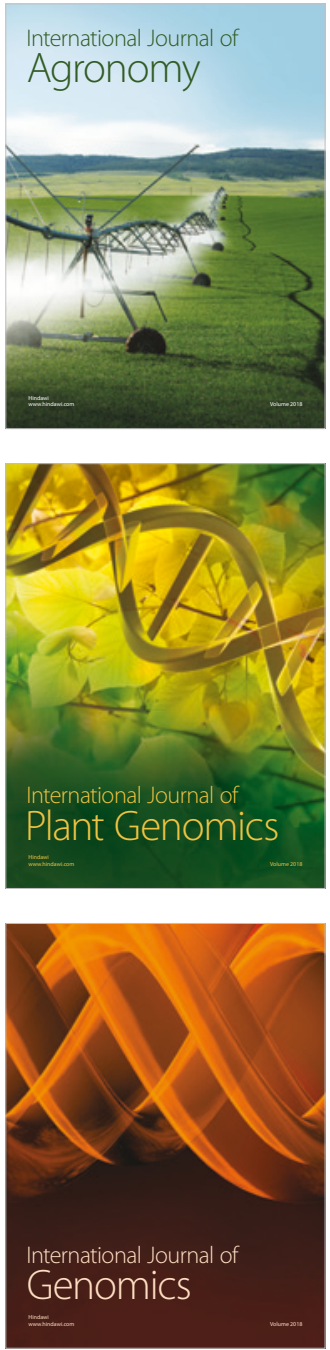

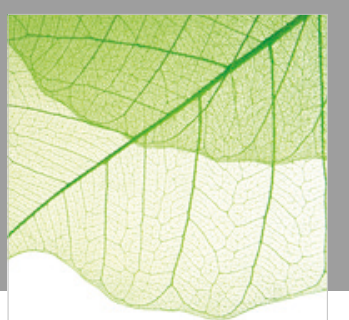

Journal of Botany
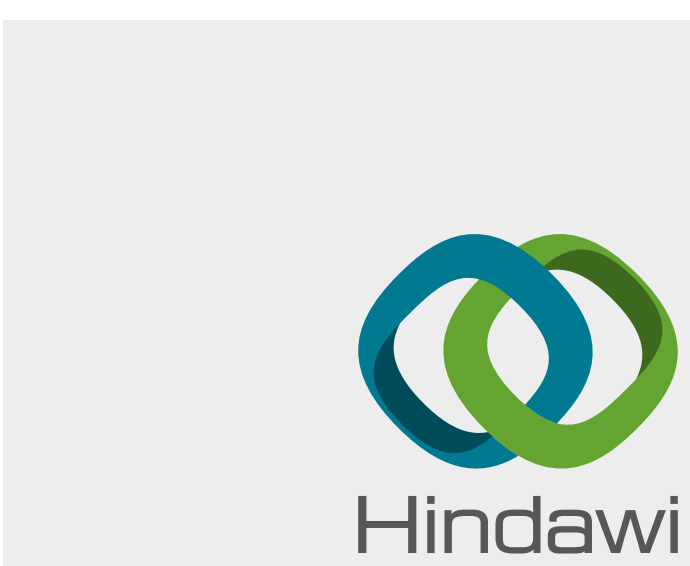

Submit your manuscripts at

www.hindawi.com
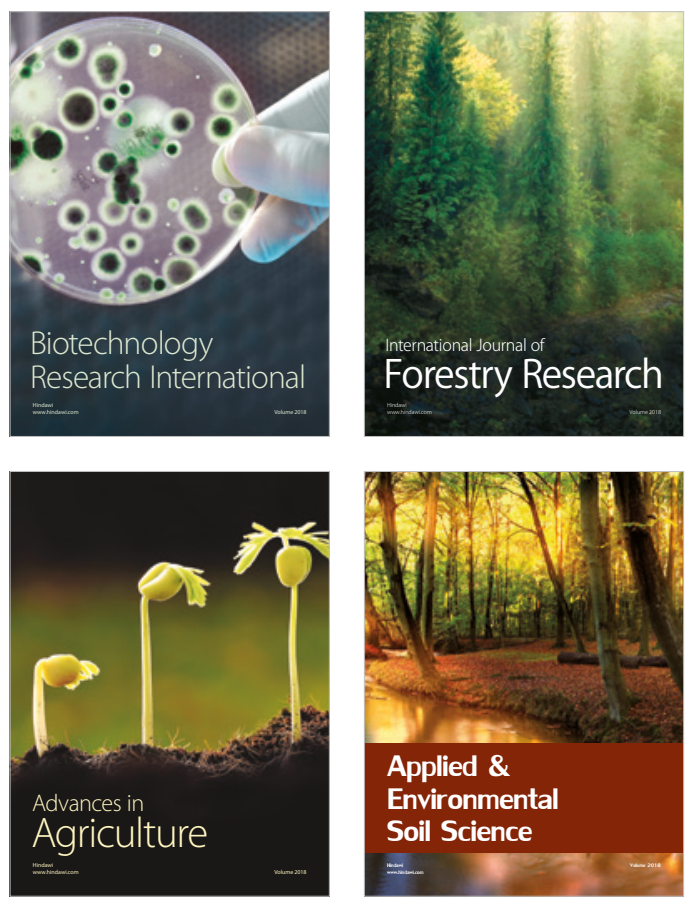

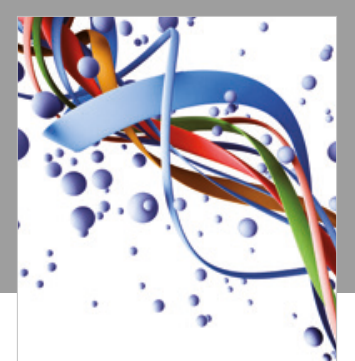

Scientifica

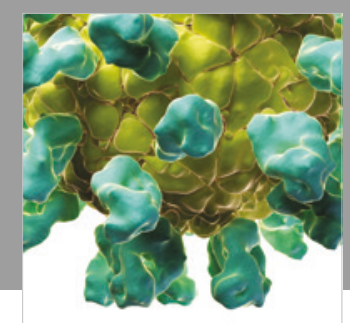

Veterinary Medicine International

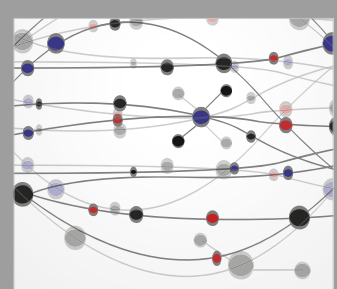

The Scientific World Journal
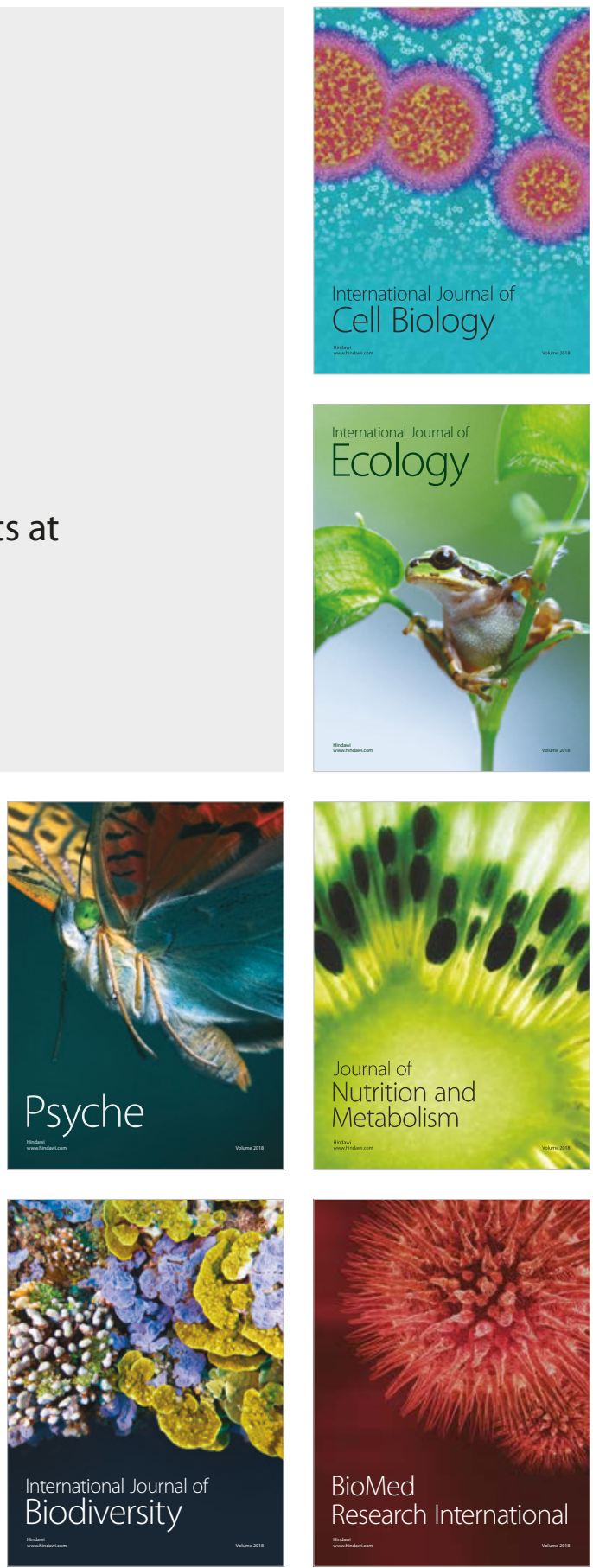